\title{
Photolurking, An Example of Digital Disorder Within the Context of Digital Privacy Phenomenon in Turkey
}

\author{
Koç N. E. ${ }^{1}$ \\ ${ }^{1}$ Nur Emine KOÇ, İstanbul Aydın University, (Turkey) \\ e-mail: nurkoc@aydin.edu.tr
}

\begin{abstract}
The increase of social media addiction causes problems in using these platforms especially for the teenager. By Web 3.0, social media platforms, having been used without the restrictions of time and space, has changed the definition and shape of "privacy" phenomenon in Turkey. Not only the teenagers but also all the age groups of internet users are concerned by the exposure of privacy consent phenomenon. Like Thomas Moore's "Utopia", social media platforms promise their users an everlasting spectacular world, free from responsibilities, sorrow, negativeness and disappointment of life. Without time constraints, the users in this spectacular world, experiencing the culmination of the illusion of happiness, determine the privacy limits of them within the boundaries of social media platforms, making them exist in its principles. This study aims to analyze the digital disorder, photo lurking, as a consequence of unlimited privacy exposure, within the context of privacy phenomenon, shaped by social media platforms; furthermore, what kind of photos the users share on this platform, the frequency of photo sharing and lurking of other users' photos and as a result of these, the effects of digital addiction among the users are going to be examined in this research by survey technic.
\end{abstract}

Keywords: Social Media Platforms, Privacy Exposure, Digital Addictions, Photolurking.

\section{Introduction}

In the twenty first century, people maintain their lives as a community member of digital media. Having been involved with Web 3.0 technology, crucial changes in socio- economic lives of people have occurred and communication becomes easier, faster and more interactive than old times. By these developments, especially by the easy connection of internet on mobile phones, totally changed the perspectives of people; moreover, a new culture on social media platforms has been created. Internet becomes the most powerful tool for globalization, converting people to be identical. Free from the boundaries of time and space limits, the participants on these platforms become the medium of this digital culture, leading mass media nowadays.

By their shares, comments, likes, posts and even lurking on social media platforms, the participants, not only serve that platform by creating content in it with their own consent, but also, they become the advertisement themselves. Based on McLuhan's statement "Medium is the message" (1964:112), medium is not a message transfer tool anymore, when considered that the content of the message is the participant him/herself, it turns into a mechanism that shapes the participant's perception. By social media platforms, people are able to involve in other participants' private lives, as much as they wish and wherever they are. The more the privacy is interfered, the less vulnerable it becomes; yet it is not understandable by the participants, because people feel themselves more independent, interactive, social and limitless within the boundaries of these platforms.

Digital media platforms especially social media, have converted people's perception of communication and socialization into its own culture; therefore, digital communities and identities have occurred. Having its own rules, perception of privacy has changed, too. Yet, capitalism has never been affected by this invention; on the contrary, it has turned into a huge industrialized and digitalized communication tool that mechanizes people's perceptions and turns people into obedient and dependent participants, consented to do whatever this community leads them to do. People are willing 
to be a community member of this global village, but this time being global is not enough; it is also a digital (cyber) village (McLuhan, 1989:18).

When digitalized communities are concerned, people are believed to be socialized on social media platforms. The participants of these platforms open accounts for themselves, interact with other participants online and the most important key point that gathers people united is, they accept and are being accepted by the communities that they might never been involved in their real social lives. Digital platforms, having created its own reality, shape and recreate everything in digital space according to its own rules. How these rules are created is the crucial question to be asked. The rapidness and convenience of digital media platforms are the biggest factors to be used and new digital culture is created by huge amounts of people. What are the platforms that keep these people occupied?

New media platforms, covering both digital and social networks, consist of computers, computer networks, computer-based communication, Internet, web 2.0, web 3.0, online journalism, online chat, wiki, e- trade, e- signature, digital visualization, cyber space, virtual space, digital media, digital games, digital culture, avatar and virtual reality. The social, cultural and economic phenomena that these concepts define, have become part of our daily speeches (Binark and Löker, 2011:9). According to Leah A. Lievrouw and Sonia Livingstone, "new media" involves information and communication technologies and social contexts related to them, devices that enhance communication skills, communication activities developed using these devices, and social arrangements and organizations shaped around these practices (Lievrouw, 2011:5). "New Media platforms are the artifacts and practices that enable people to communicate or share meaning in a large social and organizational arrangement (Lievrouw \& Livingstone, 2006:5). Both Livingstone and Lievrouw in their book New Media Handbook state that, the concept of new media shall avoid logic of unilinear, single causation, based on technological, social, economic or psychological reductionism, or on voluntarism (positioning the user and his or her will as the central point of the theory) (Lievrouw and Livingstone, 2006). Moreover, social media, a part of new media, is the common name given to websites that allow users to share online news, photos, videos, text, content with other participants. Participation and sharing constitute the mainstay of the social media, a tool for people to communicate and interact with each other. It is the medium; people produce and consume content (Fuchs, 2014:15). These platforms create new cyber communities, enlarging people's communication network, enabling people to create and manage their own cyber identities, increasing the speed and dissemination of information exchange, making people interactive. On the other hand, false and fake information, irrelevant details, hate speeches; dichotomies can also be served easily on these platforms in seconds. The reason why these social media platforms are spread all around the world so active and rapidly is because hidden identities and anti-social people can easily get rid of their spiral of silence mode by them. The participants can impersonate any character they wish to and share any photos to use them as their own profiles; furthermore, they can lurk any profile they want in seconds.

Social media, as the new actor of surveilance society, plays an important role for data-mining. In these platforms, while people are taking other people under supervision, they also lurk and serve their and other people's privacy to new media industry. On one hand, new communication and surveillance technologies commodify and circulate all the details of people's privacy except their consent without awareness of the individual and, on the other hand, they publicize people's privacy by creating the consent of the individual with the promise of popularization (Smythe, 2006:128-132). With or without the consent of the individual, people are being objectified; moreover, this situation recreates the industry by violating the privacy of them. In this article, a dijital disorder example "photolurking" is going to be analysed within the concept of privacy phenomenon.

\section{New Media and Privacy Concept}

Effective range of our actions, being carried out as mediated by new media in everyday life is expanding every day. In parallel to this situation, effect created by the actions can reflected to large masses and processes. Therefore, it is difficult to trace the results of these actions perceptibly. On the other hand, cyber space, where new media environments are operated, creates a unique culture, new types of relationships specific to individuals and communities. All of these bring the obligation to address actions mediated by new media and their consequences into question in the context of privacy concept. 
Many concepts such as computer, computer networks, communication with computer hardware, Internet, web 2.0, web 3.0, online journalism, online chat, wikis, e-trade, e-signature, digital media, digital game, digital culture, digital imaging, avatar, cyber space, virtual space, virtual reality and social, cultural and economic facts identified, described by them became a natural part of our everyday life. The term, which covers and unites all these terms, is "new media" (Binark and Löker, 2011:9).

Leah A. Lievrouw and Sonia Livingstone refer to the information and technologies and social contexts in connection with them, devices that increase communication capabilities, communication activities and practices developed by using these devices and social regulation and organizations formed around these devices and practices with the concept of new media (2007:23).

In both definitions, the role and importance of the culture and social organization practices emerged in this process together with the tools and environments come to the forefront in the new media.

The characteristics that distinguish new media from traditional media can be listed as digitality, interactionism, multimedia style, hypermetality, user-derived content production, propagation and the feeling of presence in the virtuality/interface. Lievrouw stated that the biggest feature that differentiates the new media from the traditional media is fact that it is ready everywhere and interactivity. (2011:5). Interaction comes to the forefront as an indispensable daily need of life especially for the $Z$ generation when it comes together with the speeding feature. This feature also allows different users to communicate with each other at an interface. Another participant may comment any content in an online site; a comment can be added to a video or visual material uploaded on the wall of a social sharing network. These comments are instant and interactive.

Coleman emphasized that the digital transformation is realized in human to human relation, not human to computer relation in his work named "Avatar" (2012:46). Multimedia style also defines the coexistence of different data types such as image, sound, text and digital data. Multimedia style feeds on the digitality of new media environments and supports user-derived content production (Binark and Löker, 2011:11). Hypertextuality is easy access to other alternative media/texts through an interface or network. This feature allows easy movement from one text to the other, access and movement in and between the texts through the interface (Aktaş, 1995:22).

Digitality and hypertextuality with interactive and multimedia style support the propagation of new media environments. A text on an interface can be propagated by transmitting them to links in social networks and from them to others by both new media professionals and the user. Widely propagated network can extend to all directions from nodes in contrast to a hierarchical order. (Coleman, 2012:26). It even continues to exist as a digital trace in cyberspace, even if a record that enters the circulation in its interface is deleted.

Virtuality is one of the most impressive features of the new media. It gives the user a feeling of existing in digital. In the 1990s, the image of virtuality is defined as they belong to the equipment used by the user, not the user himself/herself. (Lister, 2009:35). In the 21st century, virtual presence, in other words the sense of being somewhere through mediation is directly connected to the sense of being with others through mediation (Coleman, 2012: 144). According to Ralph Schroeder, if existing is the sense of being there, existing together is the feeling of being there together (147).

Another important feature of the new media is the production of user-derived content. New media presents new tools and technologies in which media content can be archived, commented on, customized and put to propagation again by the consumers and these tools reveals many subcultures, which propagates Do-It-Yourself (DIY) media production. According to Jenkins, the trends of users' which moves between mash ups (online assemblies), movies, and computer games are transforming the relationship of new media consumers with each other, media texts, and media producers. (2002). Now, communication between the attendants, which became producer/consumer through the network results in common production in addition to common consumption. Users can change the content they follow individually or collectively or create content directly (Çomu, 2010: 31). furthermore, user-derived content generation transforms the consumer into prosumer, as mentioned by Laughey (2010:66). A pro-consumer user can upload an amateur or semi-amateur video he/she 
shot to a sharing network, this visual narrative can be propagated in any social sharing network, welcomed by "like" or "dislike" feedback by other users, this way the user both get in contact with other users and the content (text and visual) is shared and propagated. User-derived content production, interactivity and virtuality/existence sense problems have occurred in terms of privacy due to unlimited share and production of the user in new media environments.

The ambiguity and uncertainty of privacy also make it difficult for them to define it. This concept, whose scope and meaning and its limits are very hard to define, means the "confidentiality and being secret" according to the Turkish Language Society. This concept, required to be examined with sociological, psychological, political and legal dimensions must have a practical quality and becomes a concept, representing a condition that expresses separations or variances and has integrated and divisive quality (Fischer and Hubner, 1998: 422-423).

Accordingly, privacy must have consistency in three different contexts:

a) Having a neutral privacy concept is necessary in terms of identifying privacy loss that may occur in individual and social life. This is also important in terms of understanding the claims and discussions regarding privacy.

b) Privacy must present a consistent or coherent integrity as a value. Therefore, it should be possible to see what is desired about privacy and whether a legal arrangement is appropriate or not.

c) Only when privacy gains the practical concept qualification in the context of law, events or conditions that require legal protection can be determined. Because law does not act to protect it against each event or situation, regardless of its value or importance in terms of person and social life. In other words, there must be a relative agreement about what is the value and the interest to be legally protected. In short, privacy must be consistent and objective as value and must be practical as a legal concept and within this frame, it must obtain a scope that will express or represent the privacy losses, attacks against privacy and actual privacy violations (Fischer and Hubner 1998:426).

Generally, privacy includes the right to draw the lines regarding being alone, freely selected thoughts and actions, attending the social life and interact with it. It states the right of free living and the independence on the existence form of a person to the extent that they will not get involved in the life of others. Privacy is a fundamental human right in modern societies and frames the freedom of human not to share him/herself with society and community. People should be able to determine the level of their share about themselves and this area of freedom should be minimized from all effects of the public (Arık, 2018:19).

Privacy can be studied in three basic features according to Fischer: spatial privacy, personal privacy and information privacy. The first one requires the protection of one's physical space, especially the house, the second one requires protection of one's body against unjust interventions and the third one requires controlling how will personal data be or won't be collected, stored, processed and distributed (1998:422). And according to Lokke, privacy is the freedom of doing anything as far from the observation of the community and self-judging, without hesitation for reactions of others, and those who are allowed to be involved in our private space, and being alone, not sharing anything when necessary (2018:22). Self-realization is a prerequisite for privacy. It covers 'private' area exempted from public in public space. Giddens highlights that the right of privacy is irreplaceable for democracy, a person is free to open his/her emotions, thoughts and actions that he/she will not open to public when he/she is alone (1992:54).

When privacy sense is handled via public space, private space and public space are implicit with each other. Public space is stated as a place as an area for emancipation, self expression, representation, sensing others, placed between the economy and the state (Habermas, 1989:17). The attendant whose privacy sense is reformed with attractive structure of new media authorities carries out disclosure of the privacy in public space sometimes willingly and regardless of his/her approval at other times.

Sense of privacy originating in the relation of personal life with social area and marking the domination of an individual on the form of existence has been formed in the axis of socio-economic changes within historic process and gained a different form with new media. 
Self-expression of an individual is also the history of gaining dominance challenge of the dominant on this area against the will of the individual. Thus, while internal or external threats to the private life of a person continue to exist in every period, the violations of privacy have evolved from traditional infiltration methods to technological infiltration methods.

While capitalist production relations which commoditize, all social processes impose a culture which is more individualist, more materialist, more competitive, based on money and under the determination of dominant environments, privacy is harmonized with the capitalize effect of life as an inevitable requirement of this modernization process. The urbanization, which has contributed to the acceleration of the process of capitalism, points to the social reality behind the changing sense of privacy. While the transformation of the community life to society life in the city culture brings private area into the forefront, taking the lid off from the private life destroys the holiness of privacy. The blurring of the distinction between the private area and the public area led to the fact that the space which was once the private space became part of the public sphere. In cities that alienate humans to their own existence, fetishist meanings are given to commoditization, and differentiation by consuming is the main determinant of search for identity (Toprak at all., 2014:25).

Along with postmodernism, consumption culture is completely integrated and individual identity search has been designed on consumption values, privacy becomes public as expression or reflection of life style more than ever before. Privacy presentation in this period, social benefit provided by the body, identity exposure caused ignoring traditional rules by many people, while individualism is being developed, private worlds of people entered into orbit of the market. While private life is being released under the control of public continuously, many power device, especially mass media tools reinforced seizure of privacy and produced a power strategy from this (Gürbilek, 1992:58).

In the big transformation from newspapers to new media, media and privacy relation is a muchdebated field, while private life is exposed frequently via mass media tools, during the commodification process of privacy, TV, radio and cinema undertook very important roles. With the development of the new media, serious changes occurred socially and economically before both the individual and the community, internet, which triggers an important industry, made communication and interaction easier than ever before. The nature of the internet, which gave the control to the receiver during mass communication process, enabled other people to get involved in private and secret lives and at the same time made them vulnerable against the interventions, which may come from other people (Postman, 1994:37).

Social media, the most important actor of the surveillance society and new media, is one of the most active fields of data mining. In this environment, users are observed while other users are being observed, and their privacy is allocated to the use of the industry. While new communication and monitoring technologies commoditize and circulate all details of a person's private life without the awareness of him/her and without his/her consent, it also depravities his/her privacy by fabricating consent of the individual with its awesome popularization promise. Industry offers domain of sovereignty to the user especially through social networking platforms, the individual who wants to shout his/her existence to the masses, in fact, gifts his/her privacy to the sovereignty of the industry. Digital technologies that objectify the individual, whether with or without consent, are fed from personal data and reproduces the industry by violating the privacy of the individual (Binark,2007:22).

\section{Modern Era and Privacy:}

According to Allen Westlin, the sources of the threats against privacy are self-revelation, curiosity and surveillance (1970:52). The privacy that expresses the right of the individual to exist on the public space is a social phenomenon and at least two people must be available in order it to be in an environment. It varies from person to person and from society to society. The feeling and the view that the person does not share with the public is his/her privacy.

In the Fordist period which creates standardization and collective consciousness in consumption, everyday life practices are similar and most of the differences are being rasped in society. In the 70s, the saturation in production could not be achieved in consumption due to the lack of sufficient demand, and the decrease in the demand for mass goods caused production surplus. Fordism, which completed its efficiency, became barren, and after the petroleum crisis, a new regulation on production 
and consumption was needed. Strict principles of Fordism was flexed and Post-Fordism period which foreseen mass production and consumption transitivity was started. In this way, capitalism has become dominant again and effectively (Yörükan, 2008, 129-180).

The origin of post-fordism is more consumption. In this context, especially through mass communication tools, it softens the resistance against commodity by directing to individual consumption and promises 'peace' to the individuals thanks to 'identities on sale', which they consider they can only obtain through commodities. The individual, who interiorizes the culture of consumption, arranges the lifestyle according to the needs of this culture and acts according to the requirements of the consumer culture when choosing their clothes, practices, experiences and opinions. In this period, morality is replaced by hedonist consumption (Zeldin, 2014:133). Image is everything according to the new orientation. The individual, who is guided by the consumer society, thinks that he can get rid of troubles with commodification, and that he will have happiness, status and peace with consumption in the fast wheel of capitalist life. This way it gains a new identity with the purchased products. The individual who identifies his social existence with consumption thinks that he will be unhappy when he loses this situation and he accepts this illusion of happiness without question (Baudrillard, 1998:97).

Consumption has become more effective not only in purchasing activities but also in leisure activities by reaching a wider mass with the introduction of new media to our lives. While the individual is pushed to the direction of the industry with the purchased identities thanks to the new media platforms in which we can interiorize the show business, privacy concept is commoditized with this and reproduced by the consumption culture, which can keep freedom under control.

The actors of consumption culture lead to the commodification of consumption not only with consumption products but also with their own selves in the culture created by the social movement. In other words, they commoditize with their own consent or involuntarily through their own bodies and individualities (Featherstone, 1991:146). This situation is also settled by the triggering of globalization. The search for identity, status, consumption, and the effort to exist in the consumer society as an individual have extended the limits of privacy and caused the boundaries of the public space and the private space to be intertwined. Many individuals who prefer capitalized identities do not hesitate to present their privacy to the public during this period and they actually give up their privacy when they reveal their lifestyle.

Media authorities, who direct individual to consumption through mass media, lead to the commodification of the individual in every aspect and internalization of the thought dynamics of the consumer society with the reality offered by the media. As it was specified in Manufacturing Consent: The Political Economy of the Mass Media book of Edward Herman and Noam Chomksky, commodification phenomenon with mass media tools are possible with the production of consent. Like in the film "Rambo" given as an example by Chomksy, Rambo becomes an important figure in Vietnam War as an American soldier rather than Vietnamese people in the film. By perception operation, the audiences are thought to be in the place of Rambo rather than Vietnamese people, because he is the hero and the survivor of the war as an American soldier. Nobody questions the role of Rambo there as an American in Vietnam (Herman\&Chomsky, 1988:70).

\section{Surveillance Society and Privacy}

\section{Photolurking Disease and Digital Privacy Phenomenon}

\section{Social Media Platforms}

Social media platforms discussed in this study through Facebook and Instagram have occupied not only American and European users but also Turkish ones with their interactive usage, data sharing of multimedia content and system that is available to create content fast and easily. Turkey, which we used to seeing at the bottom of any European and American lists, is well up on the list of use of social media platforms. While users who want to escape from the intensity of daily life, heavy responsibilities and fast, pace of this century we live in try to blow off their momentary steam and relax in these near hand platforms, which have curiosity impulse removal, and socializing features, in the meantime they contract digital diseases without noticing. These platforms cause several psychopathological and sociological problems, especially when being used unconsciously symptoms of cigarette; alcohol and drug use is seen on users. Along with the early diagnosis of 
symptoms originating from this addiction, newly defined in Turkey, actions taken to make provision against these symptoms and to create conscious users beforehand have a huge importance.

The first two of the most widely used social media platforms in Turkey are undoubtedly Facebook and Instagram. Exemplifications are given on these applications because of the abundance and variety of their users and exorbitance of photo sharing were taken into consideration.

Facebook was founded on 4 February 2004 by a Harvard student, Mark Zuckerberg, and it was originally called "The Facebook". In the beginning Facebook was a free application, developed to make Harvard students communicate with each other. However, Facebook won recognition of its users and became popular outside Harvard University at short notice. Facebook's primarily aim is to enable people communicate with their friends. In order to communicate with their friends, Facebook users use features such as note, status update, photograph, video etc. This led to the birth of a concept called "social network website". In the light of these developments the number of Facebook members surpassed 5.5 million. In the year, 2008 in addition to many services it offers Facebook managed to preserve its popularity with games such as "Farm Ville". The same year people began to invite their friends to join Facebook, in the way Facebook doubled its number of members and reached 10 million. In 2009 Facebook, introduced "like" feature/concept. In the meantime, concept of "like" has become a stubborn fact in today's pop culture. By 2013, an important part of world population had already begun to use Facebook. Facebook became a focal point for not only ordinary users, but also publicists and firms that want to increase their brand value. As of 2010, Facebook became $2^{\text {nd }}$ most visited website in the world. Mark Zuckerberg whose global success increased incrementally, was chosen "person of the year" by Time Magazine. What is worth noticing in here is that other than its social usage such as communication, photo sharing, information transfer, Facebook turned into a suitable channel for firms that want to reap profit in terms of economy. Facebook keeps renewing itself by adding features such as creating activity, live streaming, story sharing and in 2019 it reached approximately 2,13 billion users (url1).

Instagram was founded on March 2010 by Kevin Systrom and Mike Krieger under the name of Burbn. In its first week, Instagram met 200.000 users. This number reached 1.75 million in two months and then to 4 million in three months. An infographic group called Visually, published an infographic which shows that Instagram's net worth went from 0 to 1 billion dollars in 17 months. In January 2011 by creating their own hashtags Instagram, put a feature, which helps users to find other people or photographs easily into use. In March 2011, Instagram reached 5 million users. In August 2011, it reached 150 billion photographs. In September 2011, Instagram 2.0 was launched. In this new version, different filters and livelier image quality were added. Thus, Instagram reached 10 million users. In April 2012, Instagram had reached 30 million users and launched its Android based application. The application was downloaded 1 million times in a day. Facebook bought Instagram, which received a 50-million-dollar investment, for 1 billion dollars, which doubled the value of Instagram in one week. Today it has 37 million users with a net worth jumped to 500 thousand dollars from 50 thousand dollars. Instagram and Facebook that are very popular in Turkey became the most popular applications with their quality, easy usage of photo sharing and filtering features. Application, which became prominent with its tagging/tagged feature is commonly preferred by young people because of other features such as short videos and live streaming. In two applications which private, friends only and public options are available to its users' participants can continue their existence both with their real or fake identity (url2).

\section{Why do we want to share photos on social media platforms?}

One of the two main reasons for that is the desire to be recognized and considered important. Today, almost everyone shares photos on social media platforms for several reasons. Business or entertainment driven shares can be viewed by limited followers or everyone, copied and shared by other users without permission. This issue addressed as both morality problem and violation of privacy is an indication of that every step taken in our consumption-oriented world is realized for the purpose of presentation to the industry. If the most important reason behind the widespread use of consumption is globalization then the most important factor that makes globalization affective is social media platforms. In the $21^{\text {st }}$ century, which we live in as digital media actors of show business, any kind of private information is turned into a data used by media authorities and private information of individuals made available for dominant powers via social media platforms especially Facebook and Instagram. Moreover, since it is not even possible to know who watches us in modern surveillance 
systems, all the confidential information of participants whose data and preferences are stored via a panoptic system that constantly watches them is served as a public domain. It is observed that the balance that Foucault explained in the context of power and competence was established on social media platforms. In the applications where the participants share their privacy with consent through creating content, the distribution of information can be easily spread from private to general, and the media authorities reinforce their power with this interactive production / consumption relationship. When content becomes an advertisement, other participants who consume it interact in the direction of their daily practices which liking a content becomes a natural part of it and applying the same thing for themselves then they motivate themselves to this desire of sharing (Foucault, 1977:45-87).

On the other hand, participants desire to exist on Facebook and Instagram is shaped on reflecting our emotional world on these platforms, increase popularity and some relational, personal identity factors. Received and given responses, communities that formed in social, political, emotional and religious respect make both original contents producing and re-sharing of a liked content essentials of these applications. Moreover, mostly in these applications funny, specific shares without heavy information content are created. Participants share their happy moments in general and serve Debord's show business that he foresaw. According to Debord, every content produced in the media is a showoff and these showoffs reproduce the competence of the media every time, making its continuity irrevocable. The participant who tries to exist with the identity s/he created in the show business, becomes the first one to believe the reality of digital world that s/he created then comes other participants who are sheltering to cyber world from cruelty of the real world (Debord, 1994:56).

In a world where media reality becomes digital media reality, participants who see happiness form of creating a status on social media platforms want to reinforce this situation of being considered important by sharing everything they do in these platforms. While reinforcing that they become goods. Every content produced, every photo shared brings that person into existence in these platforms and these people turn into advertisement themselves.

It is scientifically proven that the illusion of happiness also occurs in brain perceptions. By triggering brain's reward system, social media platforms ensure the sense of acceptance to be met in digital reality and address the participants' perception of satisfaction. Since positive emotional reactions received on these platforms stimulate brain's nucleus accumbency (satisfaction area), the positive mobility towards the brain increases as positive affirmation increases. When the number of likes received on applications such as Facebook and Instagram are increased, participants go through flow state (growth in pupils) condition (Köse, 2010:8).

On the other hand, the need of the like / dislike button on these platforms is not different from the bond established in the real world. It is mutual. While likes and comments left for the purpose of entertainment, self-identification, strengthening relations, supporting and establishing oneself provide happiness in individual sense, it also ensures the continuity of these platforms in terms of media authorities.

In today's world where the positive aspects of social media platforms are at the forefront, we came to a position where we do not care about the importance of digital traces we left in these platforms in terms of disclosure and violation of our privacy. Each social media account is an identity work the participant created for oneself and is shown only as much as the participant allows. During the construction of this identity, individuals can draw a line between real life and themselves by not revealing any information or image they do not like concerning their lives. These platforms have the power to turn people into a news, an advertisement and media itself with only one smartphone which has the enough equipment to reach a wide range audience easily and that is the reason of why the whole world is gathered around them.

For example, the song of a Korean band called Blackpink, received 63 million views with the help of social media platforms in two hours. Before that a Korean singer, Psy, influenced the whole music market in the world with his song Gangnam Style. These types of shares which suggests that users of these platforms can be famous any time, rule out the fact that users turn themselves into goods and increases these platforms' marketing value. In the focus of the desire to be liked there is nothing left from neither privacy fact nor Marx's vision of surplus value. In these platforms where every step we take can be spied out through digital marks we left and every participants' information is open 
to circulation through data mining, it is improper to mention privacy. In this study, the transformation of concept of privacy into digital and its final form in Turkey is aimed to be unfolded.

In this digital age that the concept of privacy is ignored, digital diseases that are constantly added new definitions such as fomo (fear of missing out), cyberchondriac, cheesepodding, Facebook depression, phubbing, histrionic personality disorder, internet rage, nomophobia, egosurfing, google tracking, stalking, photolurking started to be discussed and taken part in literature in Turkey. These digital diseases, defined to raise social awareness, causes the reason of participants' who were proven to spend approximately 6 hours on digital platforms every day to question themselves. Living a life that does not include digital platforms is of course against the necessities of our time but both in terms of defining borders of privacy and participants who manage to control the condition of being attached to digital world without turning it into addiction will continue to remain as users not slaves of digital platforms.

In this study, photo lurking digital disorder, directly proportionate to the concept of privacy is discussed. When the high rate on public photo sharing on Facebook and Instagram, phenomenon of existing of desire to be liked and triggering factors of being recognized is combined, rules set by society were changed. Just as cultural phenomenon changed on conventional media platforms via tv shows, cultures formed in digital platforms also underwent some changes in this age. In the course of this change, addictions that were ignored, came to the surface.

\section{Camera}

The word "photograph" is a compound word based on the Greek words photo, meaning "light," and graph meaning "drawing, writing," together meaning "drawing with light." Photograph is created by the gathering of electromagnetic radiation reflected from objects. The most commonly encountered photographs are the ones that created with wavelengths that create permanent images visible to human eye. Johann Zahn designed the camera in 1685. In his book, there are sketches of a camera called camera obscura, very similar to today's. However, Johann Zahn's idea of camera did not/could not go beyond sketches. The first photograph was taken by Nicéphore Niépce in 1814. Thousand years before the first design of camera an Iraqi scientist, Ibn Al-Haytham, discovered that silver nitrate tarnishes on sunlight. In his book The Optics which was written in 1021 he mentioned a kind of device similar to camera. In $15^{\text {th }}$ century Leonardo da Vinci managed to reflect images of outer world from a little hole in the dark room and that became one of the most important beginnings of the history of photography. It is impossible to save images with first cameras and they are very large. The first banausic photograph was taken by Louis Daguerre in 1829 however, the production of an effective technique called daguerreotype took nearly 10 years. Louis Daguerre and Niepce did joint work. They explained the process of obtaining a photograph on a copper panel covered with silver in a booklet. Louis and Niepce's children sold the rights of process of photograph taking to French government(url3).

Many people tried to develop this technology later on. The inventor who invented salt print and clotype processes is one of the pioneers of photographic processes of $19^{\text {th }}$ and $20^{\text {th }}$ centuries. Hamilton Smith obtained the patent of tinttypes in 1856. In 185, Frederick Scoff Archer had developed wet plate negatives then discovered dry plate negatives in 1879 .

In 1888 George Eastman produced first portable cameras. He launched Kodak cameras which had gelatin film rolls covered with bromide that can take 10 exposures in Kodak cameras. That invention gave photographers chance to move easily. After photograph was taken camera was being sent to factory, there gelatin film roll was sorted from paper then replaced on a glass, after that camera was filled with film again and returned to the owner. George Eastman, flexible roll film in 1889. Color photograph was started in 1940 on trading level. That became the beginning of photography and taking photos easily with a handy camera (Berger, 2015:45-75).

The age of digital camera began with Eugene F. Lally. The year was 1961 when he suggested the idea and his aim was to taking photographs of stars and planets to give information about astronauts' location. A Texas Instruments employee Willis Adcock obtained patent for digital cameras but could not actualize it. Steven Sasson, an engineer worked at Kodak, invented the first digital camera in 1975. 
After the invention of digital camera with the help of algorithms and artificial intelligence taking photographs with smartphones, circulation and sharing of them on social media were provided. Since the first day of its invention photograph, became one of the most important inventions of humanity and satisfied individuals' desire to be liked and exposure. Platforms, which its printing became useless and insufficient that allow multiple exposures quickly, transferred to virtual platform with the help of smart phones. Photographs which addresses individual's side of sharing, to be liked and exposure used to be printed in a dark room but today this habit is moved to digital media platforms more easily and quickly. Since social media platforms moved its participant masses to smart phones participants whom all digital habits have changed digitalized their habits such as taking photographs with smart phones which became an inseparable part of their life, sharing and checking on others' photos (Berger, 2015:80).

Because smart phones are not used to recreation or make waiting time bearable and smart phones are always connected to internet and work fast with the help of social media platforms that are with us anytime, anywhere, we began to spend time checking not only our photos but also others'. Especially young generation make their continuity permanent through smart phones, they prefer digital sociality by staying away from real life and its sociality. As a result of digital sociality one of the addictions we face are constant sharing photos (phubbing) and tracking photos (photo lurking).

When being searched on the internet the word photo lurking means tracking somebody's photos for hours (url4). The word lurks (url5) contains secrecy which means that it is the act of tracking somebody's photos secretly.

According to Nietzviecki, the desire of sharing on social media platforms is a way of declaring our individualism and now 'peeping culture' is formed (2010:15). In this digitalizing world, peeping and to be peeped became a need. Impulse of being liked and appreciated hindered private life and blurred the line between privacy and publicity. The feeling of wondering others and to be wondered about led to the ignoration of violation of privacy. Users, who focused on exposing the identity they built on social media platforms, began to both share their own photos and wonder about others' instant shares and exposure of their private life in the fast flow of life. Individual's need of peeping, which is reinforced with the reality of television and tried to be given by conventional media through reality shows, became faster and more intense with social media. The fact that both famous and ordinary people share photos on applications such as Facebook and Instagram that show a sequence from their life made both identities the same. This concept of becoming the same causes ordinary people to think that one day they can also be famous. Your tubers, artists and singers who became famous via social media platforms were liked because of what they shared on these applications and everything they did was approved. For instance; Turkish your tubers Danla Biliç, Orkun Işıtmak and Enes Batur. In this case the exposure of identity with consent and the change in the perception of privacy became inevitable.

In these platforms, while fluid, unmediated, fast moving and unsupervised information are added every second the participant who miss them out naturally feels deprived. Tracking of social media platforms on smart phones sits in natural flow of life. While working, listening the lecture, being busy, having 5 minutes of spare time or having trouble with something this is the first thing that comes to people's mind to do, it's the most common way of recreation. People do not wait to go home or find a place to be by themselves to get away from boring environments anymore. In fact, they do not even realize these boring environments.

While social media equals to satisfaction and desire to be visible to users' who have the desire to peep, socialize and become popular; people began to live in the public eye like they never did before and this situation is quickly becoming ordinary. While digitalized lives under the domination of peeping culture become permanent, all these contents have a meaning in utterly different places and contexts. In such environment where everything related to individuals become goods, our happiest moment can make someone unhappy, most shameful moments can turn into somebody else's entertainment and there is no way back from the digital traces we live behind whether it's good or bad.

When the participants who turn their privacy into an advertisement with a share button, cannot both track profiles and actualize their desire to exist fall into an emotional void, feel anxious and 
deprived. Because of this feeling of deprivation, psychopathological and sociological diseases began to manifest itself. Especially young people have hard time to concentrate, make an eye contact with others (because their eye is on smart phones), understanding and they shut oneself down to the environment completely. It is known that in further levels such symptoms as hand tremors, which is also seen in substance users', dyspnea (shortness of breath), and dizziness is observed. This situation will be discussed in detail in the findings part of the study.

\section{Method and Purpose of The Study}

The purpose of this study is to research the perception of privacy with a focus on digitalization in social media, which is the most active use of new media platforms, becoming a necessity of technological age. They become the reasons and factors of the change in this perception of privacy between $\mathrm{Z}$ and $\mathrm{Y}$ generations, the reasons behind liked, disliked and shared photographs on social media and awareness and extensity level of photo lurking disease in Turkey and revelation of symptoms of this disease. In this study, questionnaire technique is used in order to acquire data. For the questions which questionnaire technique was inadequate, face-to-face meeting technique is utilized.

\section{Population and Sample of the Study}

Study population is constituted by students of İstanbul Aydın University School of Foreign Languages Translation and Interpreting (English) department. The sample of the study is formed of İstanbul Aydın University School of Foreign Languages Translating and Interpreting (English) department $2018-2019$ academic year spring term $1^{\text {st }}, 2^{\text {nd }}, 3^{\text {rd }}$ and $4^{\text {th }}$ grade randomly selected students who are in the 18-35 age range. Departments within sample and number of students who participated to the study from these departments are determined as 100. Questionnaire was applied between the dates 26.03.2019- 29.03.2019 in İstanbul Aydın University School of Foreign Languages Translation and Interpreting (English) to 100 students in total who were randomly selected.

\section{Limitations of the Study}

The form of questionnaire is limited to 100 students of İstanbul Aydın University School of Foreign Languages Translating and Interpreting (English) who create and share contents on social media also active users of Instagram and Facebook. Questionnaire is prepared to set boundaries of digital privacy phenomenon created in these platforms, display how digital disease called photolurking is shaped amongst people in the 18-35 range in Turkey and make provisions for this subject.

\section{Data Collection Method}

In the study, data is collected through face to face meeting technique. Questionnaire, which consists fifteen questions, is applied to 100 students of İstanbul Aydın University School of Foreign Languages Translating and Interpreting (English) in total. While some of the questions on the questionnaire were asked to determine socio-demographic characteristics such as gender, age and income status, the remaining questions were: the frequency of sharing photos on Facebook and Instagram, the privacy limits of participants 'profiles, the frequency and habits of following other participants' profiles; as well as psychological and physical responses to deprivation of platforms, as well as the phenomenon of privacy and digital illness called photolurking. Questions which were in form of questionnaire were answered individually by participants and confidentiality of name is taken as basis on forms.

\section{Findings and Interpretation}

Under this title, the answers given by sample group which the questionnaire was applied and findings concerning these answers are stated. A research group of 100 people participated in the study. All members of research group are Instagram and Facebook users. The findings of questionnaire which was made to determine social media users' opinions about social media, digital privacy and photo lurking disease is shown at the tables below. In this respect while first four tables are related to demographic characteristics of participants others are made to measure how photo lurking disease is shaped in Turkey and participants' attitude regarding social media. 


\begin{tabular}{|l|l|l|}
\hline Valid & Frequency & Percentage \\
\hline Under 20 & 38 & 38 \\
\hline $20-25$ age range & 55 & 55 \\
\hline $25-35$ age range & 12 & 12 \\
\hline Total & 100 & 100 \\
\hline
\end{tabular}

Table 1. Participants' age distribution in the 18-35 ran

Table 1 demonstrates age distribution of participants who are in the 18-35 age range. $38 \%$ of participants are under $20,55 \%$ are in the $20-25$ age range and $12 \%$ were 26 and over. The reason behind participants who are in the 20-25 age range are predominate that they are undergraduates.

\begin{tabular}{|l|l|l|}
\hline Valid & Frequency & Percentage \\
\hline Women & 61 & 61 \\
\hline Men & 39 & 39 \\
\hline Total & 100 & 100 \\
\hline
\end{tabular}

Table 2. Participants' gender distribution

Table 2 demonstrates gender distribution of participants who answered social media questionnaire. While $61 \%$ of participants are women, $39 \%$ of them are men.

\begin{tabular}{|l|l|l|}
\hline Valid & Frequency & Percentage \\
\hline High school & 92 & 92 \\
\hline University & 8 & 8 \\
\hline Total & 100 & 100 \\
\hline
\end{tabular}

Table 3. Participants' Educational Background

Information concerning participants' educational background is shared on table 3. $92 \%$ of participants are active university students who are high school graduate. $8 \%$ of participants are already undergraduates who became active university students again.

\begin{tabular}{|l|l|l|}
\hline Valid & Frequency & Percentage \\
\hline $0-2$ hours & 5 & 5 \\
\hline $2-4$ hours & 28 & 28 \\
\hline $4-6$ hours & 37 & 37 \\
\hline 6 and above & 30 & 30 \\
\hline Total & 100 & 100 \\
\hline
\end{tabular}

Table 4. Amount of time participants spend on Facebook and Instagram

In table 4, participants were asked about how much time they spend on the internet during the day. Thus, $5 \%$ of participants chose $0-2$ hours, $28 \%$ of participants chose $2-4$ hours, $37 \%$ of participants chose $4-6$ hours, $30 \%$ of participants chose 6 hours and above option. Thus, with the highest rate of $37 \%, 4-6$ hours option was chosen. Based on these answers it is understood that participants are active internet users.

\begin{tabular}{|l|l|l|}
\hline Valid & Frequency & Percentage \\
\hline $100-150$ & 8 & 8 \\
\hline $150-250$ & 24 & 24 \\
\hline $250-300$ & 39 & 39 \\
\hline $300-420$ & 29 & 29 \\
\hline Total & 100 & 100 \\
\hline
\end{tabular}

Table 5. The Number of Friends Facebook Users Have

Table 5 classifies Facebook application users inside the research group according to number of friends they have. Since there was a limitation on being a Facebook and Instagram user, there is no participant not using Facebook. It is observed that there is no user of Facebook application inside the 
research group who has less than 150 friends. $8 \%$ of the participants have Facebook friends between $100-150$ people, $24 \%$ have $150-250,39 \%$ have $250-300$ and $29 \%$ have $300-420$ friends. Based on these data questionnaire was made with participants who have approximately 300 friends on Facebook.

\begin{tabular}{|l|l|l|}
\hline Valid & Frequency & Percentage \\
\hline & & \\
\hline $100-185$ & 5 & 5 \\
\hline $185-256$ & 20 & 20 \\
\hline $256-350$ & 30 & 30 \\
\hline $350-443$ & 45 & 45 \\
\hline Total & 100 & 100 \\
& & \\
\hline
\end{tabular}

Table 6. Number of Friends Instagram Users Have

In table 6, Instagram's participant rate is shown. According to the table, $5 \%$ of users have the lowest rate of 100-185 friends, while the highest rate of $45 \%$ have between 350 and 443 friends. In accordance with the questionnaire made, when compared to Instagram number of friend's people have in the age range 18-35 is higher than Facebook.

\begin{tabular}{|l|l|l|}
\hline Valid & Frequency & Percentage \\
\hline $\begin{array}{l}\text { Following } \\
\text { Facebook agenda }\end{array}$ & 85 & 85 \\
\hline Spending time & 92 & 92 \\
\hline Entertainment & 83 & 83 \\
\hline Online shopping & 15 & 15 \\
\hline $\begin{array}{l}\text { Checking their own } \\
\text { photos }\end{array}$ & 76 & 76 \\
\hline $\begin{array}{l}\text { Checking others' } \\
\text { photos }\end{array}$ & 88 & 88 \\
\hline Other & 7 & 7 \\
\hline Total & 446 & 100 \\
\hline
\end{tabular}

Table 7. Participants' Purpose of Facebook Usage

For the questions asked in table 7, participants were given the right to give multiple answers. When evaluating the questionnaire, it is seen that with the highest rate of $92 \%$, participants use Facebook to spend time. The closest to that with a rate of $88 \%$ of participants who use Facebook to check other people's photos. Then comes following of Facebook agenda with a rate of $85 \%$. Agenda following and the desire to check other participants' profiles are directly proportionate with each other. While $83 \%$ of participants are entertainment oriented, $7 \% 6$ of them check photos of their own. When other reasons are ruled out participants who are in the 18-35 age range use Facebook for online shopping with the lowest rate of $15 \%$. 


\begin{tabular}{|l|l|l|}
\hline Valid & Frequency & Percentage \\
\hline $\begin{array}{l}\text { Following } \\
\text { Instagram's } \\
\text { agenda }\end{array}$ & 90 & 90 \\
\hline Spending time & 93 & 93 \\
\hline Entertainment & 91 & 91 \\
\hline Online shopping & 92 & 92 \\
\hline $\begin{array}{l}\text { Checking their own } \\
\text { photos }\end{array}$ & 85 & 78 \\
\hline $\begin{array}{l}\text { Checking others' } \\
\text { photos }\end{array}$ & 96 & 96 \\
\hline Other & 3 & 3 \\
\hline Total & 550 & 100 \\
\hline
\end{tabular}

Table 8. Participants' Purpose of Using Instagram

For the questions asked for table 8, participants were given the right to give multiple answers. According to questionnaire, when the usage of Instagram is examined, it is observed that participants with a rate of $96 \%$ use this application to lurke other people's photos. When other reasons are ruled out, participants with the highest rate of $85 \%$ prefer this application to check their own photos. When compared to Facebook, Instagram by a long way (92\% to $15 \%)$ is a platform for online shopping for participants who are in the 18-35 age range.

\begin{tabular}{|l|l|l|}
\hline Valid & Frequency & Percentage \\
\hline Every 4 hours & 33 & 33 \\
\hline Once a day & 45 & 45 \\
\hline $\begin{array}{l}\text { On a specific day } \\
\text { of the week }\end{array}$ & 15 & 15 \\
\hline $\begin{array}{l}\text { When something } \\
\text { important occurs }\end{array}$ & 7 & 7 \\
\hline Total & 100 & 100 \\
\hline
\end{tabular}

Table 9. To determine how often participants', share photos on Facebook and Instagram

In response to the question asked in table $9,45 \%$ of users share photos from Facebook and Instagram once a day. $33 \%$ of them share photos every 4 hours, and $7 \%$ of participants share photos only when something important occurs.

\begin{tabular}{|l|l|l|}
\hline Valid & Frequency & Percentage \\
\hline $\begin{array}{l}\text { Family } \\
\text { photographs }\end{array}$ & 10 & 10 \\
\hline $\begin{array}{l}\text { Newborn } \\
\text { photographs }\end{array}$ & 30 & 30 \\
\hline $\begin{array}{l}\text { Sexually explicit } \\
\text { photographs }\end{array}$ & 35 & 35 \\
\hline $\begin{array}{l}\text { Violent } \\
\text { photographs }\end{array}$ & 40 & 40 \\
\hline $\begin{array}{l}\text { Any photograph } \\
\text { can be shared }\end{array}$ & 15 & 15 \\
\hline Total & 130 & 100 \\
\hline
\end{tabular}

Table 10. To determine what type of photos participants, see as private and will not/cannot share them on Facebook and Instagram 
In table 10, participants were given the right to give multiple answers. According to the questionnaire data, $40 \%$ of the users stated that they did not approve sharing of violent photos, $35 \%$ of sexual photos, $30 \%$ of newborn photos, and $10 \%$ of family photos on Facebook and Instagram applications and did not share such photos before. However, $15 \%$ of participants indicated that any photograph can be shared and were shared by them on these applications.

\begin{tabular}{|l|l|l|}
\hline Valid & Frequency & Percentage \\
\hline $\begin{array}{l}\text { My profile is only } \\
\text { open to family } \\
\text { members }\end{array}$ & 5 & 5 \\
\hline $\begin{array}{l}\text { My profile is only } \\
\text { open to my } \\
\text { friends. }\end{array}$ & 22 & 30 \\
$\begin{array}{l}\text { My profile is } \\
\text { open everyone } \\
\text { except a few } \\
\text { people I blocked }\end{array}$ & 30 & 43 \\
\hline $\begin{array}{l}\text { My profile is } \\
\text { public }\end{array}$ & 13 & 100 \\
\hline Total & 100 & \\
\hline
\end{tabular}

Table 11. To determine privacy limits of participants' Facebook and Instagram profiles

In table 11 participants' limits on Facebook and Instagram applications is questioned. Participants use public profile with the highest rate of $43 \%$, while the lowest is $5 \%$ including people who use their profile only open to their family members. Amongst 100 participants, there is no user having their profile in dedicated mode.

\begin{tabular}{|l|l|l|}
\hline Valid & Frequency & Percentage \\
\hline $\begin{array}{l}\text { use my real } \\
\text { identity on } \\
\begin{array}{l}\text { Facebook and } \\
\text { Instagram }\end{array}\end{array}$ & 79 \\
\hline I don't use it & 21 & 21 \\
\hline $\begin{array}{l}\text { I also have a fake } \\
\text { account }\end{array}$ & 25 & 25 \\
\hline Total & 125 & 125 \\
\hline
\end{tabular}

Table 12. To Determine Whether Shares on Facebook and Instagram Reflects Real Personality or Not

Questions asked for table 12 participants were given the right to give multiple answers except I use it/l do not use it options. While $79 \%$ of participants stated that they use Facebook and Instagram with their real identity, $21 \%$ stated that they exist on these applications without using their real identity. Furthermore, $25 \%$ of them indicated that they have both personal and fake accounts.

\begin{tabular}{|l|l|l|}
\hline Valid & Frequency & Percentage \\
\hline Strongly agree & 14 & 14 \\
\hline Agree & 13 & 18 \\
\hline Neutral & 7 & 11 \\
\hline Disagree & 50 & 50 \\
\hline Strongly disagree & 16 & 7 \\
\hline Total & 100 & 100 \\
\hline
\end{tabular}

Table 13. Violation of Privacy on Facebook and Instagram

For this question, the definition of privacy was available in the forms. In table $13,50 \%$ of participants disagree and $16 \%$ strongly disagree with the idea of privacy is being violated on Facebook and Instagram applications. It is stated that $14 \%$ of participants strongly agree, $13 \%$ of participants agree and $\% 7$ of participants is neutral with this idea. 


\begin{tabular}{|l|l|l|}
\hline Valid & Frequency & Percentage \\
\hline Strongly agree & 45 & 45 \\
\hline Agree & 32 & 30 \\
\hline Neutral & 9 & 9 \\
\hline Disagree & 11 & 11 \\
\hline Strongly disagree & 3 & 3 \\
\hline Total & 100 & 100 \\
\hline
\end{tabular}

Table 14. To measure the sense of deprivation when they stay away from Facebook and Instagram

In table 14, participants stated that when they stay away from Facebook and Instagram applications, $45 \%$ of them definitely feel sense of deprivation while $32 \%$ feel sense of deprivation, $9 \%$ is neutral, $11 \%$ do not feel sense of deprivation and $3 \%$ definitely do not feel sense of deprivation. According to table, $77 \%$ of participants stated clearly that when they do not use Facebook and Instagram applications, they feel sense of deprivation.

\begin{tabular}{|l|l|l|}
\hline Valid & Frequency & Percentage \\
\hline I feel anxious & 30 & 30 \\
\hline I feel very anxious & 18 & 18 \\
\hline I feel restless & 60 & 60 \\
\hline I feel very restless & 22 & 22 \\
\hline I feel left out & 41 & 41 \\
\hline I feel out of touch & 37 & 37 \\
\hline $\begin{array}{l}\text { I suffer from } \\
\text { physical ailment } \\
\text { (shaking hands, } \\
\text { dizziness/shortness } \\
\text { of breath etc.) }\end{array}$ & 17 & 17 \\
\hline Total & 225 & 100 \\
\hline
\end{tabular}

Table 15. To measure feelings when participants stay away/deprived from Facebook and Instagram

For table 15, participants were given the right to give multiple answers. When being deprived from Facebook and Instagram applications, $60 \%$ of participants stated that they feel restless, $41 \%$ feel left out, $37 \%$ feel anxious about being out of touch with social media platforms, $30 \%$ feel anxious, $22 \%$ feel very restless, $18 \%$ feel very anxious and $17 \%$ suffer from physical ailment. Since participants were given the right to choose multiple answers, it is observed that when being deprived from Facebook and Instagram, participants are affected from almost every hitch in the questionnaire.

\section{Results and Recommendations}

$55 \%$ of participants are in the $20-25$ age range. While women constitute $61 \%$ of participants, men constitute $39 \%$ of them. Since participants are university students; $92 \%$ of them are high school graduate and still university students. When the time participants spend on Facebook and Instagram is examined, it is seen that $37 \%$ of them spend $4-6$ hours, $30 \%$ of them spend 6 or more hours, $28 \%$ of them spend 2-4 hours on social media platforms. This proves that participants are in the 19-25 age range 4.5-5 hours of a day on social media platforms. When number of friends that the participants have is examined, it is seen that with the highest rate of $39 \%$ people have $250-300$ friends on Facebook, while this rate is $45 \%$ on Instagram, which equals to $350-443$ friends.

According to data, friends' rate of people who are in the 18-35 age range have more friends on Instagram than Facebook. This also shows that Instagram is preferred compared to Facebook by people of that age range. When being asked about the purpose of usage of Facebook application, $92 \%$ of them gave the answer of spending time, while $88 \%$ of them said that their purpose was to check other people's photos. $85 \%$ of participants stated that they log in to the application to follow 
Facebook agenda. $96 \%$ of Instagram users stated that they use this application to check others' photos, $93 \%$ of them use it to spend time, $92 \%$ for online shopping. According to findings collected from two data, $96 \%$ of Instagram users and $88 \%$ of Facebook users use these applications to check other people's photos. Instagram is accepted as a widely used application.

When being asked about how frequently they share photos on these platforms, $45 \%$ of participants replied as once in the morning, 33\% replied as every 4 hours. According to that, photos they check is more important than their own photos. The rate of photograph sharing in both of these applications is very high.

For the questions about perception of privacy on Facebook and Instagram applications, they were asked about type of photographs that they will not/cannot share on these platforms. $40 \%$ of the participants stated that they will not share violent photographs, $35 \%$ stated that they will not share sexually explicit photographs, $30 \%$ newborn photographs and $15 \%$ of them stated that anything could be shared. $10 \%$ of participants indicated that they would not share family photographs.

When privacy of profiles is taken into consideration, it was seen that $43 \%$ of them use public profiles. This condition shows that revelation of privacy with consent and desire to exist on social media platforms is more important than the boundaries of privacy for the people who are in the 18-35 age range.

$79 \%$ of Facebook and Instagram applications users stated that use real identity. While $25 \%$ of them said that they have fake accounts in addition to their real ones, $21 \%$ of them said that they did not use their real identity. The fact that real identity usage is high in these applications proves that these applications are used as "existence indicators".

$50 \%$ of participants think that violation of privacy does not occur on Facebook and Instagram applications. In addition to that, $16 \%$ of participants stated that they never joined to the violation of privacy on these platforms. When being deprived from social media platforms, $45 \%$ of participants indicated that they "definitely feel deprivation", while $32 \%$ of them indicated that "they feel deprivation". Contrary to that $14 \%$ of participants said that they did not feel the sense of deprivation.

When staying away from these applications, $60 \%$ feel restless, $41 \%$ feel ruled out, $37 \%$ feel out of touch, $30 \%$ feel anxious, $22 \%$ feel very restless, $18 \%$ feel very anxious and $17 \%$ suffer from physical ailment according to participants' answers. In this part of the research, it is confirmed that there is no one who did not suffer from anxiety, exclusion, restlessness and physical ailment. Participants are in the 18-35 age range; clearly feel sense of deprivation of social media platforms.

\section{Conclusion}

With the transition of digital addiction from desktop to smart phones, new media platforms that wraps up the people of $21^{\text {st }}$ century have become more effective and widespread. User who got used to have connection with the internet in every second of their lives, facing both positive and negative sides of this technology in a time where they are wrapped up with smart phones, they must cope up with digital diseases that are newly defined.

As a necessity of technological age, the internet has become an indispensable part of life and created an order that generations grow up to become more and more distant from life yet users' interacting via internet. User profile that develops a lifestyle disconnected from interpersonal communication cares more about digital socializing than being social on real life and creating new commune systems. This digital culture, creating its own culture and terminology is affecting masses day by day and inholding more and more users regardless of an age range. For a while, we have been taking part in this culture vulnerably and without thinking about its negative sides, amongst these platforms the ones we became most attached/dependent on are social media platforms. Just like in the 1980's when usage of cigarette was encouraged and used in every media platforms without considering harms of smoking, social media platforms have also been available for vulnerable users' for a long time. 
With the help of new media, manufacturing consent project reached to large masses more easily and effectively. As of post-Fordism period with the rediscovery of the body, it has turned into goods faster and more effectively because of physically liberating societies. Transition of concept of privacy became visible with the exposure of the body and perfection of the body began to take place of ideological functions. (Baudrillard, 2004: 163). Body stopped being a personal property and became a consumption item designed to leave a consumption effect on commonwealth and to turn others on. With the reduction of the body to a consumption and status symbol on societal level, boundaries of privacy began to be specified by the market. (Ritzer, 1998:112). With the presentation of privacy and the societal benefits of both body and identity, exposure came with the ignorance of traditional rules for many people. During this period, individualism came to forefront and individuals' private lives went into orbit of the market. While private life is being served to the market increasingly under the control of Commonwealth Day by day, many devices of power supported the exposure of privacy and finally developed a power strategy. Exposure of the body is a power project that fastens consumption is turned into a project where social missions are being produced. Perception of privacy has changed, and boundaries became blurry with the figural designing of the body. (Köse, 2011:164). During this period body reduced to an object presented to society and turned into an identity, having been redesigned through consumption. Boundaries of privacy is not being defined by traditions and the culture of the society but from the market itself.

As a result, just like in the Cave Allegory of Plato's The Republic, we accept everything presented to us without questioning and reject the rest of the reality. We do not live attached to the digital cave we live in; we are dependent to that. In this cave, which we assume that we are freer, we need to learn not to see reality as an illusion like the shadows of a puppeteer projecting on the wall. Here, in a place where virtually and reality intertwined we need to retain reality in order to stay away from the factors of social media platforms that enslaves us so that this new technology we use a means does not enslave us. It is just like what Dom Cobb said in the movie "Inception": "Dreams feel real while we are in them. It is only when we up that we realize something was actually strange."

\section{References}

[1] Aktaş, C. (1995). Mahremiyetin Tükenişi. İstanbul: Nehir Publishing.

[2] Arık, E. (2018). Dijital Mahremiyet. İstanbul. Literatürk Academia.

[3] Berger, J. (2015). Bir Fotoğrafı Anlamak. (Beril Eypoğlu, Trans.). Facsimile: Metis Publishing.

[4] Baudrillard, J. (1998). The consumer society: Myths and structures. London: Sage Publications Ltd.

[5] Baudrillard, J. (2004). Tüketim Toplumu. (Hazal Deliçaylı-Ferda Keskin, Trans.). İstanbul: Ayrıntı Publishing.

[6] Bauman, Z. 1925-2017. (2000). Liquid Modernity. Cambridge, UK: Malden, MA: Polity Press.

[7] Binark, M. and Löker, K. (2011). STÖ'ler için Bilişim Rehberi. STGM, Ankara.

[8] Coleman, B. (2012). Hello Avatar: Rise of the Networked Generation. London: The Mit Press. p. 46.

[9] Binark, M. (2007). Yeni Medya Çalışmalarında Yeni Sorular ve Yöntem Sorunu. Yeni Medya Çalışmalarının içinde (p.21-44). Ankara: Dipnot Publishing.

[10] Çomu, T. (2010). Yeni Medyada Nefret Söylemi. İstanbul: Kalkedon Publishing.

[11] Debord, G. (1994). The Society of the Spectacle. New York: Zone Books.

[12] Featherstone, M. (1991). Consumer culture and postmodernism. London: Sage Publications.

[13] Fischer, S. and Hubner, M. (1998). "Privacy and security at risk in the global information society", Information, Communication\&Society (1:4), p. 420-441.

[14] Foucault, M. 1926-1984. (1977). Discipline and Punish: The Birth of the Prison. New York:Pantheon Books.

[15] Fuchs, C. (2014). Social Media: A Critical Introduction. Sage: Great Britain.

[16] Giddens, A. (1992). The transformation of intimacy: Sexuality, love, and eroticism in modern societies. Stanford, Calif: Stanford University Press.

[17] Gürbilek, N. (1992). Vitrinde Yaşamak. İstanbul: Metis Publishing. 
[18] Herman, E. S., \& Chomsky, N. (1988). Manufacturing consent: The political economy of the mass media. New York: Pantheon Books.

[19] Habermas, J. (1989). The structural transformation of the public sphere: An inquiry into a category of bourgeois society. Cambridge: MIT Press.

[20] Köse, H. (2010). Medya ve Tüketim Sosyolojisi, İstanbul: Ayraç Yayınları.

[21] Köse, H. (2011). Medya Mahrem. İstanbul: Ayrıntı Publishing.

[22] Laughey, D. (2010). Media Studies: Theories and Approaches. Old Castle Books: Harpenden.

[23] Lievrouw, L.A. (2011). Alternative and Activist New Media. Cambridge, Polity Press.

[24] Lievrouw, Leah A. and Livingstone, Sonia (eds.), (2006). Handbook of New Media: Social shaping and social consequences - fully revised student edition. Sage Publications London, UK. p. 1-14.

[25] Lister, M., Dovey, J., Giddings, S., Grant I, Kelly K. (2009). New Media A Critical Introduction Second Edition. London and New York: Routledge. p.35.

[26] Lokke, E. (2018). Mahremiyet Dijital Toplumda Özel Hayat. İstanbul: Koç University Publishing.

[27] McLuhan, M. (1964). Understanding Media: The Extensions of Man. McGraw-Hill: New York. p.112.

[28] McLuhan, M., \& Powers, B. R. (1989). The global village: Transformations in world life and media in the 21st century. New York: Oxford University Press.

[29] Nolan, C., Thomas, E., DiCaprio, L., Watanabe, K., Gordon-Levitt, J., Cotillard, M., Page, E., Warner Home Video (Firm). (2010). Inception.

[30] Postman, N. (1994). Televizyon Öldüren Eğlence. (O. Akınhay, trans.). İstanbul: Ayrıntı Publishing.

[31] Ritzer, G. (1998). Toplumun McDonaldlaşması. (Şen Süer Kaya, trans.) İstanbul: Ayrıntı Publishing.

[32] Smythe, D. W. (2006). Batı Marksizminin Kör Noktası, Trans: Levent Yaylagül, İçinde Kitle İletişiminin Ekonomi Politiği, Ed: Levent Yaylagül, Dalbaz Publishing: Ankara. p.127-172.

[33] Toprak, A. Yıldıım, A., Aygül, E., Binark,M., Börekçi, S \& Çomu, T. (2014). Toplumsal Paylaşım Ağı: Facebook, Görülüyorum Öyleyse Varım. İstanbul: Kalkedon Publishing.

[34] Westlin, A. (1970). Privacy and Freedom. Newyork: Atheneum Publishing.

[35] Yörükan, T. (2008). Bir ilişki düzenleme süreci olarak mahremiyet. TiSK Akademi, 4 (6). p.129-180.

[36] Zeldin, T (2014). An Intimate History of Humanity. London, United Kingdom: Vintage Publishing.

[37] url1 https://www.biography.com/business-figure/mark-zuckerberg

[38] url2 http://www.yeniisfikirleri.net/instagramin-basari-oykusu/

[39] url3 https://tellmewhyfacts.com/who-invented-the-camera-and-photograph/

[40] url4 https://tureng.com/tr/turkce-ingilizce/photolurking

[41] url5 https://tureng.com/tr/turkce-ingilizce/lurk 